\title{
Regenerating Retinal Pigment Epithelial Cells to Cure Blindness: A Road Towards Personalized Artificial Tissue
}

\author{
Balendu Shekhar Jha ${ }^{1} \cdot$ Kapil Bharti $^{1}$
}

Published online: 12 May 2015

(C) Springer International Publishing AG 2015

\begin{abstract}
Retinal pigment epithelium (RPE) is a polarized monolayer tissue that functions to support the health and integrity of retinal photoreceptors (PRs). RPE atrophy has been linked to pathogenesis of age-related macular degeneration (AMD), a leading cause of blindness in elderly in the USA. RPE atrophy in AMD leads to the PR cell death and vision loss. It is thought that replacing diseased RPE with healthy RPE tissue can prevent PR cell death. Retinal surgical innovations have provided proof-of-principle data that autologous RPE tissue can replace diseased macular RPE and provide visual rescue in AMD patients. Current efforts are focused on developing an in vitro tissue using natural and synthetic scaffolds to generate a polarized functional RPE monolayer. In the future, these tissue-engineering approaches combined with pluripotent stem cell technology will lead to the development of personalized and "off-the-shelf" cell therapies for AMD patients. This review summarizes the historical development and ongoing efforts in surgical and in vitro tissue engineering techniques to develop a three-dimensional therapeutic native RPE tissue substitute.
\end{abstract}

Keywords Blindness $\cdot$ Retinal dystrophy $\cdot$ Age-related macular degeneration - Transplantation · Scaffold · Retinal pigment epithelium $\cdot$ Induced pluripotent stem cells

This article is part of the Topical Collection on Artificial Tissues

Kapil Bharti

kapilbharti@nei.nih.gov

Balendu Shekhar Jha

jhabs.mail@gmail.com

1 Unit on Ocular and Stem Cell Translational Research, National Eye Institute, 10 Center Drive, Room 10B10, Bethesda, MD 20892, USA

\section{Introduction}

Visual impairment is a debilitating condition because it significantly worsens the patient's quality of life. Based on the World Health Organization global estimates, age-related macular degeneration (AMD) is the primary cause of visual impairment and blindness in developed countries. Worldwide, it is the third leading cause of blindness [1]. In the pathogenesis of AMD, dysfunction of an ocular cell type called retinal pigment epithelium (RPE) is considered to be a principal contributing factor $[2,3]$. There are two advanced sub-types of AMD, the "dry" form or geographic atrophy (GA) and the "wet" form or the choroidal neovascularization (CNV). $\mathrm{CNV}$ is caused by abnormal growth of choroidal blood vessels under the retina that leak blood leading to severe decline in vision. In comparison, GA is primarily caused by atrophy of RPE cells, which leads to the death of adjacent photoreceptors (PRs) leading to vision loss. GA accounts for the vast majority of AMD patients, and unfortunately, it is currently an untreatable disease $[2,4]$.

This review article describes historical and recent advances in RPE transplantation as a potential cell-based therapy for AMD. As detailed below, it has been suggested that replacement of atrophied RPE in CNV or GA patients with a "healthy" monolayer of RPE cells will prevent PRs from dying and vision from declining. Here, we review the various strategies that have been used in attempts to develop the optimal RPE tissue for transplantation in AMD patients.

\section{RPE Functions in Maintaining Photoreceptor Health}

As illustrated in Fig. 1 (adapted from Arnheiter et al. [5]), eye is a complex and highly organized organ system with multiple layers of distinct cell types. The neurosensory part of the retina contains multiple retinal layers and a layer of non-neuronal 
Fig. 1 Anatomy of human eye. As light enters the human eye, the central part of the visual field is projected by the PRs at the macular region of the eye. It is the death of these PR cells that starts with partial vision loss ultimately leading to blindness. Inset 1 illustrates various layers of the retina. The PR layer of the retina, including outer nuclear layer (ONL) and the outer segments (OS), is located adjacent to the monolayer of RPE cells. Inset 2 illustrates that these RPE cells are hexagonal, cuboidal, and highly polarized in nature and are oriented with their apical surface towards the PRs of the retina such that the microvilli of the RPE cells surround the outer segments (OS) of the PRs. The basal surface of the RPE cells rest on the Bruch's membrane (BM) where these cells interact with the choriocapillaries. (Adapted with permission from: Bharti et al. [5]

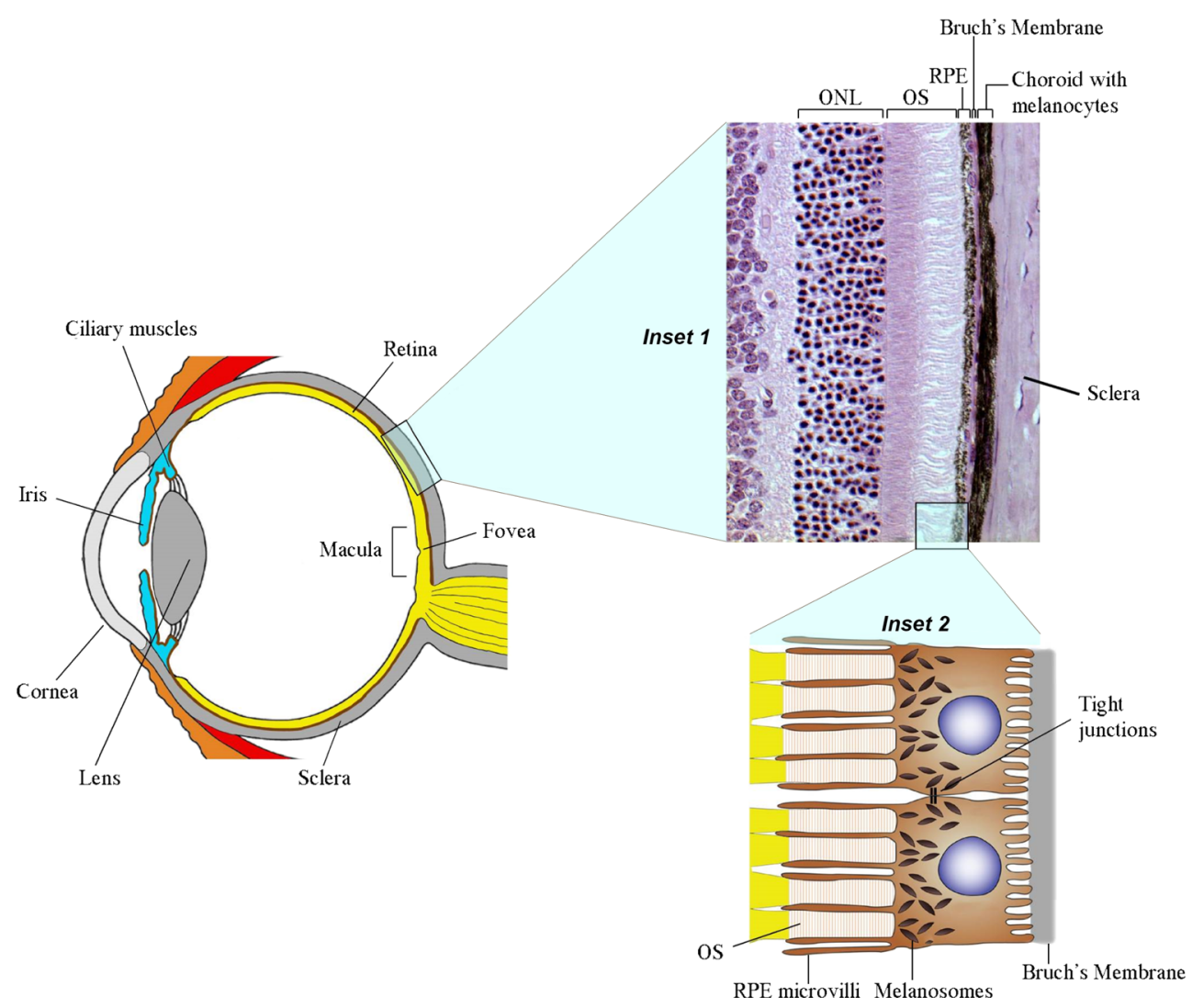

epithelial cell called the RPE. A key structural feature of RPE tissue is the highly polarized nature of its cellular monolayer. Homophilic interactions between specialized cell surface proteins on neighboring RPE cells form contacts between adjacent cells called tight junctions. These tight junctions are a key molecular determinant of RPE monolayer polarization and also contribute to the formation of the outer blood retinal barrier [6]. RPE polarization is fundamental to most of the functions performed by this tissue to maintain the health and integrity of retinal PRs throughout their life [5, 6].

For example, RPE monolayer acts as a polarized metabolic gatekeeper between the PRs and the choriocapillaries; it transports glucose and vitamin A from choroicapillaries to PRs and transports metabolites like $\mathrm{CO}_{2}$, lactate, and water to the choroicapillaries $[5,6]$. The monolayer constitutively secretes cytokines in a polarized fashion towards PR and choroicapillaries; for example, pigment epithelium-derived factor is secreted predominantly towards the apical side to PRs and vascular endothelial growth factor is secreted predominantly towards their basal side to the choriocapillaries [6]. Melanin-containing pigment granules are apically localized in RPE cells and help absorb stray light passing through the retina. The apical processes of RPE interact with PR outer segments and help recycle the photopigments to maintain normal visual cycle and phagocytose the aged tips of the PR outer segments, a process required for the renewal of these segments by PR cells $[7,8]$. Because of these critical functions performed by the RPE, its dysfunction quickly leads to PR cell death and pathogenesis with a broad range of visual impairment disorders like AMD [2, 3, 9].

\section{Transition Zone in AMD Lesion}

Histological analysis of AMD-diagnosed eyes has demonstrated that the central portion of a GA lesion, where the visual acuity drops significantly, has only few surviving RPE and PRs [10]. Therefore, an RPE transplant alone in this area will likely not provide any visual benefits. However, as illustrated in Fig. 2, the border of the GA lesion contains a transition zone where although the RPE cells have atrophied, the PR cells still are intact, but have likely dysfunctional outer segments. For this pathology, preservation of the PR cell layer in this transition zone by replacing the damaged RPE makes a practical option for cell therapy that prevents disease from progressing further $[3,11]$.

\section{A Journey Towards Successful RPE Transplantation \\ Emergence of RPE Transplantation Using Xeno-Grafts in Animal Models}

The first RPE transplant was reported by Gouras et al. in 1984 in an animal study [12]. Authors obtained human RPE post- 

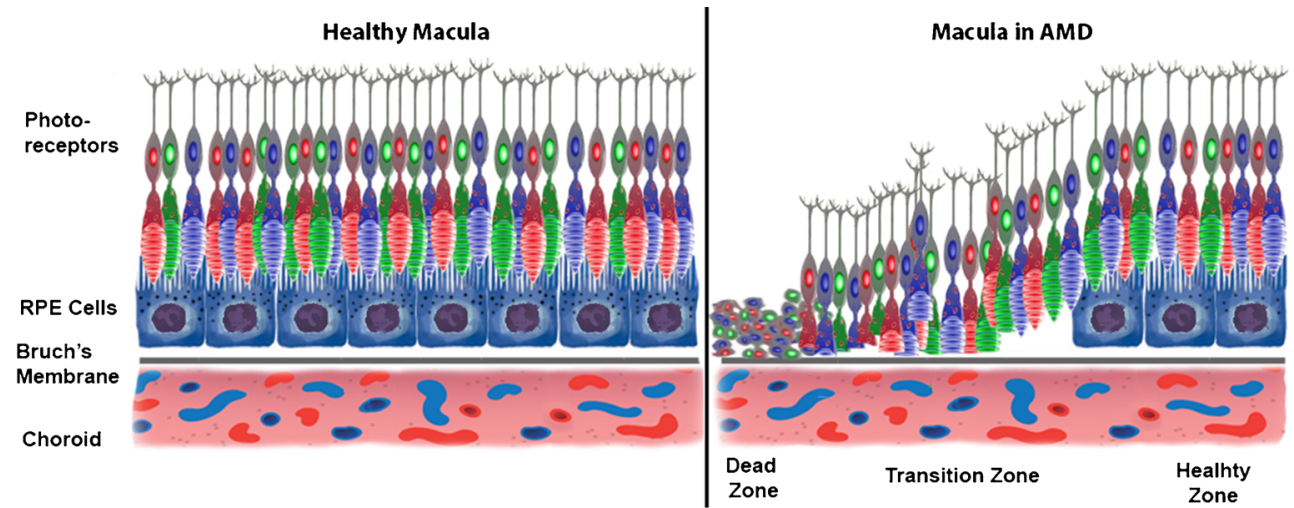

Fig. 2 Healthy macula vs. macula in AMD. In AMD, there is a "dead zone" in the macula which has minimal viable PRs and RPE cells. The healthy zone is usually towards the periphery of the macula and still has

mortem, cultured cells in vitro, and transplanted cell suspension in a monkey eye onto the Bruch's membrane where host's RPE was previously removed. These initial surgical procedures were quite invasive and involved cauterization and flapping-over of a part of retina. Subsequently, similar RPE transplant with less invasive surgical procedure were performed in rabbits [13] and in rats [14, 15]. Results from all these animal studies showed varying degrees of cell survival of human xeno-grafts. Transplantation in Royal College of Surgeons (RCS) rats, a classical model of PR degeneration caused by RPE dysfunction [14, 16], showed improved survival of PRs in the vicinity of transplanted RPE cells - possibly by reestablishing phagocytosis of PR outer segments [17-21]. This assumption was based on the fact that PR cell death in RCS rats is due to the defective phagocytosis by RPE, caused by a mutation in an RPE cell surface protein MERTK [22]. In any case, these xeno-grafts provided hope that RPE transplantation is feasible and that PR rescue with transplanted RPE is possible [23-27].

\section{RPE Allo-Grafts in Animal and Human Trials}

The success with early xeno-grafts in animal models was marginal, but it encouraged the development of next generation RPE transplants. In the 1990s, RPE sheet allografts derived from fetal [28-30] and post-mortem adult [31-34] human eyes were tested in multiple human trials. Most of these initial patients had previous incidence of extensive submacular scarring due to $\mathrm{CNV}$ and the transplantation surgery also involved removal of the submacular scar tissue. Because removal of $\mathrm{CNV}$ also caused inadvertent removal of the remaining RPE, for PR rescue in the transition zone (Fig. 2), the transplanted RPE layer was positioned in the subretinal space on top of the native Bruch's membrane in place of the native RPE layer. Radtke et al. transplanted the complete retina-RPE complex (PRs+RPE sheet) from fetal donors, which improved some visual acuity in $70 \%$ of transplanted patients, and in some functional PRs with healthy RPEs. In between, there is a "transition zone" (not drawn up to the scale) where RPE cells are dead, but the PRs are intact [7]. This is the potential target zone for RPE transplantation

patients, the improvement sustained over several years [35]. In this particular trial, the grafts survived even when there was antigen mismatch between the donors and the recipients; however, it is not the case in most of the allo-graft transplantations. In majority of trials, there was no reported long-term improvement in the visual acuity of patients and the grafts were compromised. This was likely due to edema and subsequent fibrosis caused by complications of allo-graft immune rejection, especially without a long-term immune suppression [28, 30-33, 36]. Although in a healthy eye, this site is immunologically privileged because of the outer blood-retina barrier provided by RPE monolayer; it is not considered immuneprivileged in a CNV patient or in a surgically operated eye $[30,36,37]$. Allo-graft immune rejection is most likely due to mis-matched HLA class I antigens expressed by transplanted RPE [38], and their potential to be activated to express MHC class II antigens also [39-41]. Clearly improved transplant acceptance was observed in drug-induced systemically immune-suppressed patients [33, 34]. However, long-term immune suppression often leads to severe systemic sideeffects and, therefore, to avoid the need to use long-term immune suppression in elderly patients, the RPE transplantation field shifted its focus on autologous sources of RPE.

\section{Autologous RPE Grafts}

Binder et al. pioneered autologous RPE transplantation for AMD patients [42, 43]. This first study began in late 1990s and used non-diseased autologous RPE cells harvested from the nasal subretinal region of the patient's same eye. The patients underwent subretinal membrane excision around the macular region where harvested autologous RPE cell suspension was transplanted. Patients with RPE cell transplant showed significantly improved multifocal electroretinography response density after 1-3 months post-surgery. However, long-term prognosis was not good; no significant improvement in visual acuity and central 
visual field defects were observed [43]. It is likely that the temporary vision improvement was related to the transient non-polarized cytokine secretion and non-specific phagocytosis activities of RPE suspensions injected in the subretinal space. The fate of these cells is dependent on their proper adhesion to the native Bruch's membrane and their ability to form polarized RPE monolayers. Age-related and AMD pathology-related changes in the patient's native Bruch's membrane can limit RPE cell suspension to form a polarized monolayer after transplantation [44]. In the long-term, non-adherent cells undergo apoptosis or form aggregates $[45,46 \bullet, 47]$. Some attempts were made to reinvigorate attachment of injected RPE cell to the native Bruch's membrane. For example, van Meurs et al. injected poly-L-lysine in the submacular space prior to injecting the suspension of RPE cells in their clinical study for autologous RPE transplantation in AMD patients [48]. However, the prognosis of this procedure was not promising and three out of eight patients in this study suffered ocular adverse events like proliferative vitreo-retinopathy (PVR). This outcome was likely due to reflux of RPE cells in the vitreous chamber or due to poly-L-lysine-induced PVR in the transplanted RPE cells [48]. Because of the complications associated with transplantation of RPE cells suspension and the lack of long-term visual benefits, investigators started considering transplantation of autologous RPE monolayer sheet in the form of a full thickness RPE-choroid complex. This was the first true threedimensional tissue used for transplantation in the back of the human eye.

\section{Autologous RPE-Choroidal Complex Transplants}

Several groups attempted transplantation of full-thickness autologous RPE-choroidal complex taken from the retina periphery to the damaged macular region [31, 47, 49-55]. This process was termed autologous translocation. Often this procedure was performed in patients with a prior incidence of CNV and required removal of the scar tissue and/ or an extensive submacular hemorrhage from the macular region. Combined together, the peripheral incision, submacular scar removal, and graft translocation are considered an invasive procedure and led to several cases of PVR in the eye or continuous subretinal fibrosis, eventually limiting function of the graft. However, in cases where PVR was not observed and the graft survived in the macular region, significant improvement in vision was noticed for some of the patients [51]. Overtime, this procedure was also tried on GA patients and has provided a significant proof-of-principle data that autologous RPE tissue graft can provide visual function benefits in AMD (both CNV and GA) patients [56-58].

\section{Pluripotent Stem Cell-Derived RPE for Developing In Vitro RPE Tissue}

In addition to the complications associated with full thickness RPE-choroid grafts, a big challenge in RPE replacement therapy using autologous RPE cells in suspension or sheet is the limited availability of the graft. Opportunely, in parallel with the evolution of RPE transplantation strategies, progress in the field of regenerative medicine with pluripotent stem cells was pacing forward. The establishment of a stable system of human embryonic stem cells (ESCs) culture in 1998 [59], and the discovery of the technique to reprogram human adult differentiated cells to induced pluripotent stem cells (iPSCs) in 2007 [60, 61], further opened the avenues to pursue cell therapy using allogeneic or autologous cells. Both ESCs and iPSCs have the capability to differentiate to mature cell types of any germ layer substantiating their therapeutic potential. Furthermore, in contrast to primary RPE with limited availability, supply of pluripotent stem cells is theoretically infinite.

Nonetheless, there are serious concerns for clinical translation of pluripotent stem cells that need to be addressed including risks of teratoma formation, differentiation to undesired cell types, and potential immune reactions especially when using hESC-derived RPE. From regulatory perspective, the risk of teratoma or tumor formation is relevant only for the final product. These risks can be addressed by ensuring the purity of the final product and using safety studies in immunecompromised animals. Recent work has clearly established that unless a certain number of pure pluripotent stem cells are exceeded, these potential adverse events are not initiated [62]. This is certainly advantageous for the RPE transplantation field that requires a relatively small number of RPE cells (approximately 20,000-100,000 cells) per transplant. Combining the power of pluripotent stem cell differentiation capability and surgical techniques described above provides the most optimal way forward to develop an artificial tissue for RPE replacement in AMD patients.

The first report of differentiation of ESCs into RPE-like cell was a rather serendipitous finding that utilized the socalled "spontaneous" differentiation protocol to generate "RPE-like" cells $[63,64]$. Since then, a number of groups have reproduced these early findings and others have evolved the RPE differentiation protocol into a more step-wise developmentally guided directed differentiation method [65-70]. The latter incorporates the fundamental developmental biology to generate neuroectoderm by blocking canonical WNT, and Nodal pathways. RPE or retinal progenitors are generated from these cells using TGF-inducers like ACTIVIN A [67]. Although, the overall differentiation process takes several weeks to generate pure "RPE-like" cells, it has now been optimized both from ESCs and iPSCs [67, 68, 71]. Despite the fact that significant progress has been made with RPE differentiation from pluripotent stem cells, not much 
attention has been given to extensively characterize the generated "RPE-like" cells. All the work on characterization of "RPE-like" cells obtained from ESCs/iPSCs has been based primarily on a handful of RPE-specific markers, and in vitro phagocytosis assays. The four P's of RPE characteristicspolygonal, pigmented, phagocytic, and polarized-have not been validated with these cells to call them fully-functional and authentic RPE cells (see Bharti et al. for details [5]). Moving forward, as more and more groups plan to use ESC/iPSC-derived RPE cells into clinical application, it will be critical to fully-authenticate RPE cells derived from human pluripotent stem cells. It will allow an easy comparison of cells generated by different groups and also provide robust, fully-characterized cells to move forward towards clinical application. We have performed a comprehensive analysis of RPE derived from several iPS cell lines generated from genetically and epigenetically distinct tissue sources. This work has allowed us to identify potential "release assays" that define the range within which an iPS cell-derived RPE can be authenticated (unpublished data). This work also forms the basis for developing regulatory and industry standard release criteria in the field of RPE-based cell therapies.

Transplantation of both ESC and iPSC-derived RPE cells has been tested successfully in animal models $[46 \bullet, 64$, 72-75]. Because an AMD-appropriate animal model is missing, most of these efficacy studies were done using RCS rats $[14,64,72,76]$. It, nevertheless, provided proof that human pluripotent stem cell-derived RPE can provide some visual benefits when the host RPE functions are compromised. Long-term safety studies in immune-compromised rodents have also provided sufficient safety data about these cells. In fact, the first in-human clinical trials for AMD have been started using hESC-derived RPE cell suspension [73, 77]. Schwartz et al. just recently published promising results for long-term safety (up to 36 month follow up) of hESC-derived RPE transplantation trials that were started in 2011 for GA stage of AMD and Stargardt's disease, a monogenic early onset form of macular degeneration $[73,77]$. This trial is also suggestive of visual function improvement in AMD and Stargardt's patients; however, additional patients and more extensive functional analysis is needed to fully-substantiate these claims

Similar to the work done with primary human RPE cells, these initial animal studies and the first human trial utilized injection of RPE cell suspension in the subretinal space. However, as described above, non-adherent RPEs have limited long-term survival and can lead to additional complications like cell-aggregate formation triggering innate immune response and PVR [46•, 77]. To circumvent these complications, as the next generation of pluripotent stem cell-derived RPE, several investigators started designing scaffolds to provide a substrate for the RPE cells to form and retain a monolayer sheet structure for transplantation purposes.

\section{Developing Artificial RPE Tissue Using Scaffolds}

As described above, in vivo RPE tissue is composed of a polarized RPE monolayer that sits on a proteinaceous Bruch's membrane. Transplantation studies done in animals and humans suggested that RPE cell suspension does not form an intact polarized RPE monolayer when injected in the subretinal space [78]. More importantly, this is a concern when injected RPE cells have to attach to diseased and senescent Bruch's membrane [79]. Furthermore, RPE cells suspension could efflux into the vitreous cavity and form epiretinal scar tissue or even PVR that could severely affect vision in patients $[48,77]$. These factors prompted investigators to develop RPE tissue in vitro for transplantation purposes. A number of different strategies have been tried to develop an ideal artificial RPE tissue. Cells tested have ranged from human RPE cell lines (APRE19 and D407), primary animal or human RPE cells, and pluripotent stem cell-derived RPE. There is even a greater variation in the types of scaffolds that have been tested, thus far-ranging from scaffolds made of natural or synthetic substrates (see Tables 1 and 2 for details).

Scaffolds made of natural polymers have the advantage of closely mimicking the native ECM and being biocompatible $[118,119]$. But they are often not xeno-free and are not readily available complicating their use for clinical applications. Instead, synthetic scaffolds are easily available and these can be designed to suit specific needs of transplantation including incorporation of biocompatible polymer, scaffold design mimicking ECM, and regulation of biodegradation time [118-120]. The choice of substrate is a critical parameter for a successful transplant of RPE tissue in AMD patients. In an ideal substrate, the following parameters need to be addressed [40]: (1) in vitro, the substrate should allow formation of polarized RPE monolayers that can be functionally validated to perform functions that native RPE performs; (2) the substrate should have sufficient physical strength and maneuverability to be transplanted by a surgeon in the back of the eye; (3) substrate should support RPE monolayer engraftment and integration to the host's Bruch's membrane; (4) substrate should be inert to host eye; and (5) substrate should facilitate and not impede polarized RPE functions. It is not certain if the substrates tested so far listed in Tables 1 and 2 meet all these key requirements. It is possible that because of some of these reasons, most of these tissue-engineering approaches listed in these Tables were not followed further towards pre-clinicial or clinical studies (with the exception of RPE sheet on polyester substrate [108, 121], on parylene-C substrate [115], and substrate-degraded RPE sheet with iPSC-RPE [122•]). Among all of these efforts, the only artificial tissue that has moved forward into a clinical phase utilizes minimal scaffolding [122•]. In this study, iPSC-derived RPE cells were grown on collagen I, 


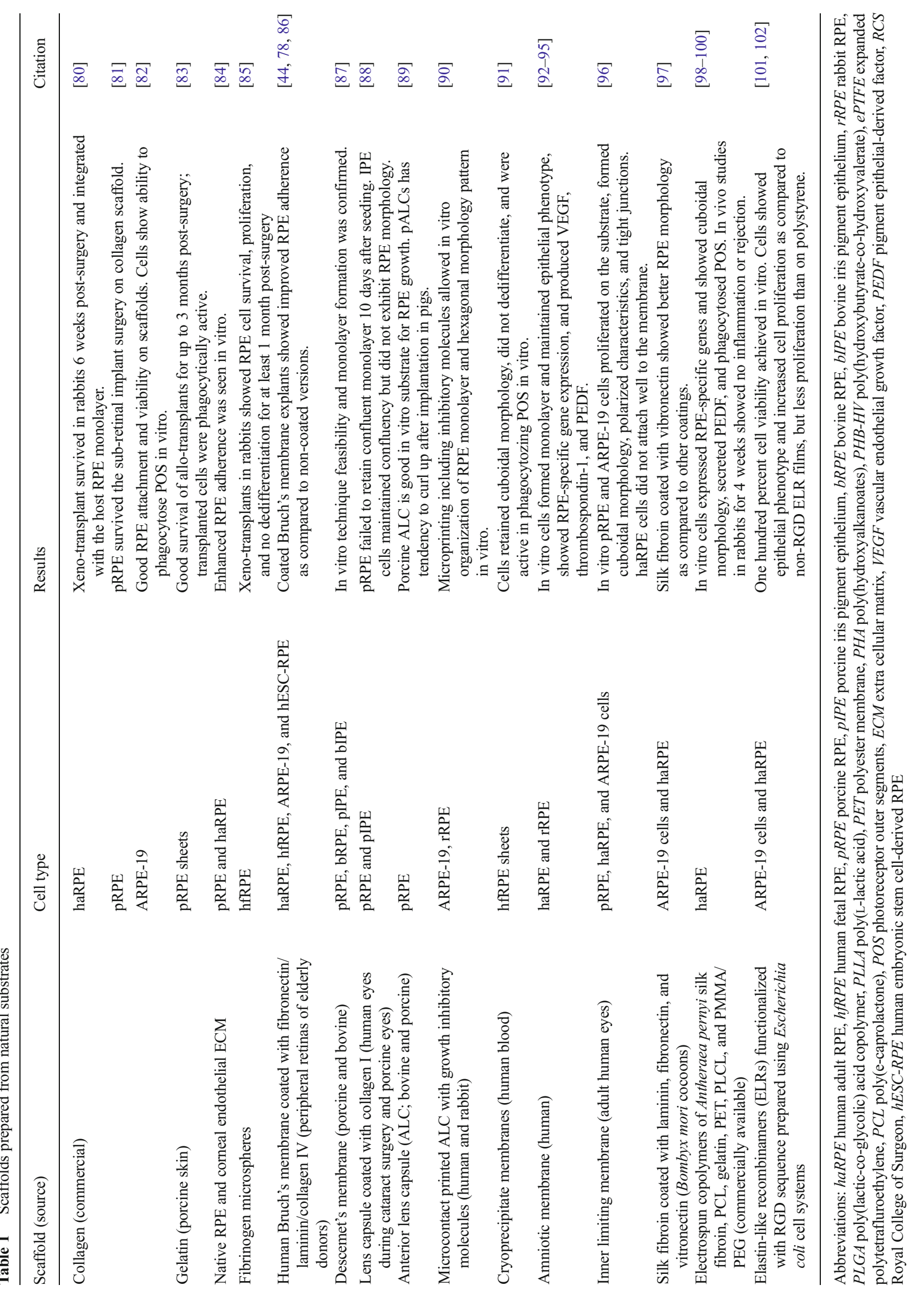




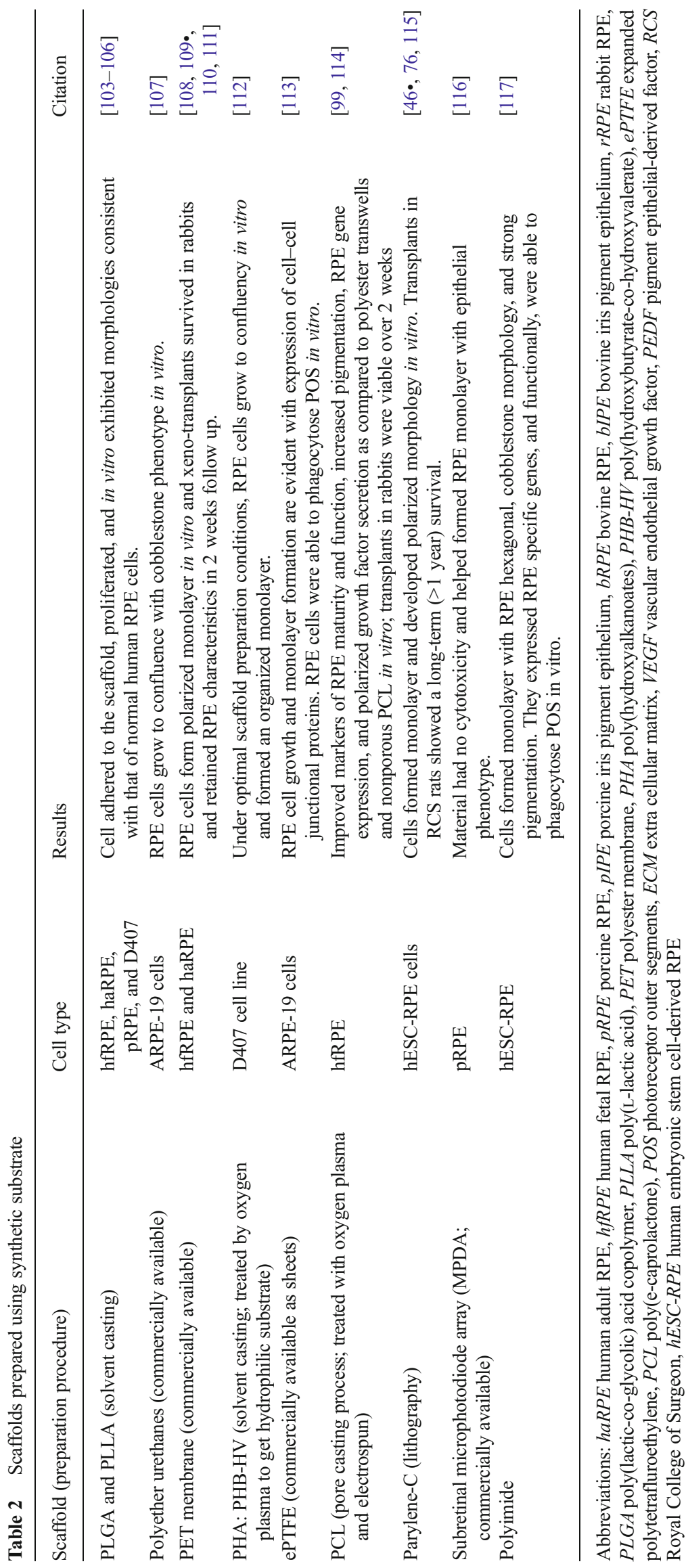


which was removed using a mild collagenase treatment to isolate a pure RPE sheet. This construct has been tested in autologous and allogeneic settings in monkey models [122•] and recently was transplanted as first in-human iPSC-trial [123]. Another approach to isolate scaffold-free pure RPE sheet that was tested in vitro and in vivo was using temperature-responsive culture dishes created by grafting poly ( $N$-isoporpylacrylamide) on general cell culture dishes [124-126]. In these customized culture dishes, reducing the temperature from 37 to $20{ }^{\circ} \mathrm{C}$ changes the culture surface from being hydrophilic to hydrophobic. This allows RPE cell culture and maintenance at one temperature and non-enzymatic harvest of the intact RPE sheet with its secreted ECM at the lower temperature. Using this approach, in vitro assays of ARPE-19 cells [124] and in vivo studies with homologous transplant of rabbit primary RPE cells [127] yielded promising results.

It is clear that the combination of tissue-engineering and regenerative medicine approaches is yielding a new generation of RPE tissues that have a significantly improved likelihood of leading to a successful clinical product (illustrated in Fig. 3). A word of caution is that limited characterization has been performed on in vitro engineered RPE tissue so far (Tables 1 and 2). In many cases, RPE cells were shown to form confluent monolayer and have epithelial morphology in vitro $[46 \cdot, 76,82,83$, 87, 90-96, 98, 101-107, 109•, 110, 112, 113, 115, 116]. Some extended their observations to limited molecular and in vitro functional characterizations of RPE tissues [82-84, 91, 94, 95, 98, 113, 114]. Because of the experimental manipulations involved in generating the cells and the scaffolds, in vitro-developed tissues need to be fullyvalidated before they are moved into pre-clinical or clinical development stage. Ongoing work in our laboratory is trying to set benchmarks and develop standard assays that can be used to authenticate RPE cells grown on artificial scaffolds (unpublished data). We propose such standard

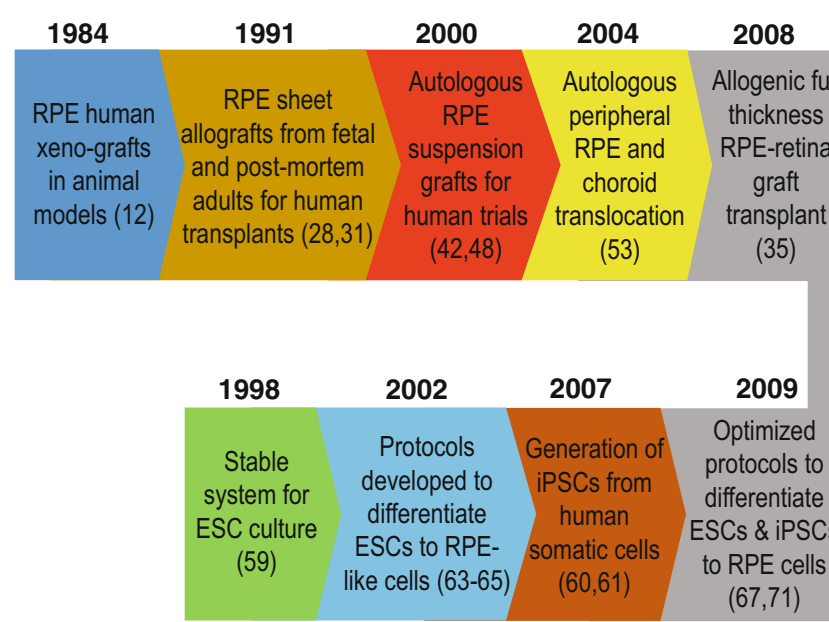

Fig. 3 Roadmap to personalized “off-the-shelf” RPE-based cell therapies assays be tested across multiple laboratories to confirm their reproducibility so that they can be adopted to various ongoing clinical efforts using stem cell-derived RPE.

\section{Regulatory Requirements for Cell Based Therapies}

To progress stem cell based RPE therapies from pre-clinical to clinical stage, regulatory approval is required to ensure that the potential therapy is efficacious and does not pose any reasonable danger to the health of the patient. The surgical techniques described above do not require an approval from Food and Drug Administration (FDA); they can be approved at the level of Institutional Review Board. However, all the stem cell based therapies need to be approved by the FDA as well. Unfortunately, there are no streamlined guidelines for iPS cell based products yet because of lack of any approved clinical product presently in this category. Center for Biologics Evaluation and Research (CBER) is a part of FDA regulating the cell-based therapies and their commercial applications. CBER regulates stem cell based products under 21 Code of Federal Regulations (CFR) 1270 and 1271. For instance, it ensures that manufacturing process for stem cellbased products is strictly controlled and does not expose the patient to any communicable disease or adventitious pathogens. Such rules are more stringent for allogeneic products that can be used for an entire population as compared to autologous products that are patient specific. Another important aspect that CBER wants to ensure is that stem cell-based products do not lead to unwanted tumor or teratoma growth after implantation in patients. When using iPS cells to develop a cell therapy, it is not clear what kind of standard assays will be required to prove non-tumorogenic nature of the final clinical product. RPE transplants are unique in this aspect, because only a small number of cells are required for the transplant, thus, reducing the possibility of an individual cell proliferating untowardly. Nevertheless, an approval of a stem cell based therapy from the FDA requires a thorough demonstration of safety and

$\begin{array}{ccccc}2006 & \mathbf{2 0 0 9} & \mathbf{2 0 1 2 - 2 0 1 4} & \mathbf{2 0 1 4} & \\ \text { hESC-RPE } & \text { iPSC-RPE } & \text { Phase I of } & \text { Autologous } & \text { HLA-matched } \\ \text { implanted in } & \text { suspension } & \text { hESC-RPE } & \text { iPSC-RPE } & \text { off-the-shelf } \\ \text { RCS rats } & \text { implanted in } & \text { suspension } & \text { patch } & \text { iPSC-RPE } \\ \text { rescue visual } & \text { RCS rats } & \text { transplant } & \text { implanted in } & \text { patch } \\ \text { functions } & \text { rescue visual } & \text { completed } & \text { AMD patient } & \text { availability } \\ (72,74) & \text { functions }(75) & (73,77) & (87) & \end{array}$


toxicity profile and proof-of-principle potency of the clinical products in preclinical animal models. For autologous cell therapies, there is an additional need to demonstrate consistency and reproducibility of the process across multiple patients. Ocular regenerative medicine field is exceptional because it has already paved the way for embryonic stem cell-based therapies by facilitating the first potential therapy in the eye [123], It is likely that ocular regenerative medicine field will also lead in the case of iPS cell-based therapies and provide the entire field of regenerative medicine with a streamlined process for obtaining FDA approval for stem cell based therapies.

\section{A Road Towards Personalized Medicine}

The use of autologous iPSC-derived RPE potentially provides the advantage of eliminating complications caused by immune rejection. Although these autologous cells will carry the genetic mutations associated with the primary cause of AMD, our unpublished work suggests that there is no AMD-like pathology in these cells at the time when they are ready for transplantation. Furthermore, the autologous cellbased therapy will trail-blaze its way through regulatory hurdles in developing iPS cell-based therapies and provide a streamlined process for more innovative approaches in the future. Several innovative ideas are being tested in the field, including generation of MHC-matched iPS cell lines and universal donor stem cell lines [128-130]. These new approaches will provide an immune-match with the patient and likely be more successful "off-the-shelf" clinical product for AMD patients (Fig. 3). Advances listed here project an easy and successful path towards RPE replacement therapies in the near future. As the next step, efforts will need to focus on more audacious initiatives that aim to replace not just the RPE monolayer but also the layer of degenerated PRs [131, 132].

Multiple clinical trials that utilize a combination of pluripotent stem cell-derived RPE and different kinds of scaffolds have been planned for the coming few years (for details see Bharti et al. [133]. There are high hopes that some of these trials will lead to a new potential therapy for AMD. These ongoing studies are poised for success because of several enabling technologies that have been developed over the years in ocular regenerative medicine including minimally invasive surgical techniques [40,43], non-invasive outcome measures [40], proof-of-principle surgical procedures demonstrating success of autologous RPE grafts [42, 48], RPE differentiation from ES and iPS cells [63, 65-67, 71], tissue-engineering to develop stem cell-derived RPE tissue [131, 132], and proofof-principle ES and iPS cell-derived RPE transplants in AMD patients $[73,77,123]$. Once the safety and efficacy aspect of this tissue-engineering approach is well-established and accepted in the field, the next goal will be to make these approaches into commercially viable strategies. However, appropriate reference standards need to be established that will allow a comparison of different clinical products, allow testing of safety and efficacy of these products, allow manufacturing process scale-up and scale-out, and guarantee success at the commercial stage. We suggest the need for a dialogue between regulatory agencies, like the FDA, and other important stakeholders like National Institutes of Health, National Institutes of Standards and Technology, and industry partners to develop reference standards for the field of RPE-based cell therapies.

Acknowledgments This work was supported by the National Eye Institute Intramural Funds and NIH Common Fund Therapeutic Challenge Award.

\section{Compliance with Ethics Guidelines}

Conflict of Interest Balendu Shekhar Jha declares that he has no conflict of interest.

Kapil Bharti has a patent PCT/US2014/014160 pending.

Human and Animal Rights and Informed Consent This article does not contain any studies with human or animal subjects performed by any of the authors.

\section{References}

Papers of particular interest, published recently, have been highlighted as:

- Of importance

1. Resnikoff S, Pascolini D, Etya'ale D, et al. Global data on visual impairment in the year 2002. Bull World Health Organ. 2004;82(11):844-51.

2. Ambati J, Fowler B. Mechanisms of age-related macular degeneration. Neuron. 2012;75(1):26-39.

3. Gouras P, Lopez R. Transplantation of retinal epithelial cells. Invest Ophthalmol Vis Sci. 1989;30(8):1681-3.

4. Holz FG, Strauss EC, Schmitz-Valckenberg S, van Lookeren Campagne M. Geographic atrophy: clinical features and potential therapeutic approaches. Ophthalmology. 2014;121(5):1079-91.

5. Bharti K, Miller SS, Arnheiter H. The new paradigm: retinal pigment epithelium cells generated from embryonic or induced pluripotent stem cells. Pigment Cell Melanoma Res. 2011;24(1):2134.

6. Bharti K, Nguyen MT, Skuntz S, Bertuzzi S, Arnheiter H. The other pigment cell: specification and development of the pigmented epithelium of the vertebrate eye. Pigment Cell Res. 2006;19(5):380-94.

7. Edwards RB, Szamier RB. Defective phagocytosis of isolated rod outer segments by RCS rat retinal pigment epithelium in culture. Science. 1977;197(4307):1001-3.

8. Mazzoni F, Safa H, Finnemann SC. Understanding photoreceptor outer segment phagocytosis: use and utility of RPE cells in culture. Exp Eye Res. 2014;126(0):51-60.

9. Zarbin MA. Current concepts in the pathogenesis of age-related macular degeneration. Arch Ophthalmol. 2004;122(4):598-614.

10. Bird AC, Phillips RL, Hageman GS. Geographic atrophy: a histopathological assessment. JAMA Ophthalmol. 2014;132(3):33845 . 
11. Kvanta A, Grudzinska MK. Stem cell-based treatment in geographic atrophy: promises and pitfalls. Acta Ophthalmol. 2014;92(1):21-6.

12. Gouras P, Flood MT, Kjeldbye H. Transplantation of cultured human retinal cells to monkey retina. An Acad Bras Cienc. 1984;56(4):431-43.

13. Lopez R, Gouras P, Brittis M, Kjeldbye H. Transplantation of cultured rabbit retinal epithelium to rabbit retina using a closedeye method. Invest Ophthalmol Vis Sci. 1987;28(7):1131-7.

14. Lopez R, Gouras P, Kjeldbye H, et al. Transplanted retinal pigment epithelium modifies the retinal degeneration in the RCS rat. Invest Ophthalmol Vis Sci. 1989;30(3):586-8.

15. Li L, Turner JE. Transplantation of retinal pigment epithelial cells to immature and adult rat hosts: short- and long-term survival characteristics. Exp Eye Res. 1988;47(5):771-85.

16. Strauss O, Stumpff F, Mergler S, Wienrich M, Wiederholt M. The Royal College of Surgeons rat: an animal model for inherited retinal degeneration with a still unknown genetic defect. Cells Tissues Organs (Print). 1998;162(2-3):101-11.

17. Li LX, Turner JE. Inherited retinal dystrophy in the RCS rat: prevention of photoreceptor degeneration by pigment epithelial cell transplantation. Exp Eye Res. 1988;47(6):911-7.

18. Sheedlo HJ, Li L, Turner JE. Photoreceptor cell rescue in the RCS rat by RPE transplantation: a therapeutic approach in a model of inherited retinal dystrophy. Prog Clin Biol Res. 1989;314:645-58.

19. Sheedlo HJ, Li L, Turner JE. Functional and structural characteristics of photoreceptor cells rescued in RPE-cell grafted retinas of RCS dystrophic rats. Exp Eye Res. 1989;48(6):841-54.

20. Li L, Sheedlo HJ, Turner JE. Chapter 20. Long-term rescue of photoreceptor cells in the retinas of RCS dystrophic rats by RPE transplants. Prog Brain Res. 1990;82(0):179-85.

21. Li L, Turner JE. Optimal conditions for long-term photoreceptor cell rescue in RCS rats: the necessity for healthy RPE transplants. Exp Eye Res. 1991;52(6):669-79.

22. D'Cruz PM, Yasumura D, Weir J, et al. Mutation of the receptor tyrosine kinase gene Mertk in the retinal dystrophic RCS rat. Hum Mol Genet. 2000;9(4):645-51.

23. Whiteley SJO, Litchfield TM, Coffey PJ, Lund RD. Improvement of the pupillary light reflex of Royal College of Surgeons rats following RPE cell grafts. Exp Neurol. 1996;140(1):100-4.

24. Sauvé Y, Klassen H, Whiteley SJO, Lund RD. Visual field loss in RCS rats and the effect of RPE cell transplantation. Exp Neurol. 1998;152(2):243-50.

25. Lund RD, Adamson P, Sauvé Y, et al. Subretinal transplantation of genetically modified human cell lines attenuates loss of visual function in dystrophic rats. Proceedings of the National Academy of Sciences. 2001;98(17):9942-7.

26. Lund RD, Kwan ASL, Keegan DJ, Sauvé Y, Coffey PJ, Lawrence JM. Cell transplantation as a treatment for retinal disease. Prog Retin Eye Res. 2001;20(4):415-49.

27. Lund RD, Ono SJ, Keegan DJ, Lawrence JM. Retinal transplantation: progress and problems in clinical application. J Leukoc Biol. 2003;74(2):151-60.

28. Algvere PV, Berglin L, Gouras P, Sheng Y. Transplantation of fetal retinal pigment epithelium in age-related macular degeneration with subfoveal neovascularization. Graefes Arch Clin Exp Ophthalmol. 1994;232(12):707-16.

29. Algvere PV, Berglin L, Gouras P, Sheng Y, Kopp ED. Transplantation of RPE in age-related macular degeneration: observations in disciform lesions and dry RPE atrophy. Graefes Arch Clin Exp Ophthalmol. 1997;235(3):149-58.

30. Weisz JM, Humayun MS, Eugene de Juan J, et al. Allogenic fetal retinal pigment epithelial cell transplant in a patient with geographic atropy. Retina. 1999;19(6):540-5.

31. Peyman GA, Blinder KJ, Paris CL, Alturki W, Nelson Jr NC, Desai U. A technique for retinal pigment epithelium transplantation for age-related macular degeneration secondary to extensive subfoveal scarring. Ophthalmic Surg. 1991;22(2): $102-8$.

32. Zarbin M, Sugino I, Castellarin A, Fine S, Berger J, Maguire M. RPE transplantation for age-related macular degeneration. Agerelated macular Degeneration. Philadelphia: Mosby Year Book Inc; 1999. p. 363-82.

33. Del Priore LV, Kaplan HJ, Tezel TH, Hayashi N, Berger AS, Green WR. Retinal pigment epithelial cell transplantation after subfoveal membranectomy in age-related macular degeneration: clinicopathologic correlation. Am J Ophthalmol. 2001;131(4):472-80.

34. Tezel TH, Del Priore LV, Berger AS, Kaplan HJ. Adult retinal pigment epithelial transplantation in exudative age-related macular degeneration. Am J Ophthalmol. 2007;143(4):584-95. e2.

35. Radtke ND, Aramant RB, Petry HM, Green PT, Pidwell DJ, Seiler MJ. Vision improvement in retinal degeneration patients by implantation of retina together with retinal pigment epithelium. Am J Ophthalmol. 2008;146(2):172-82. e1.

36. Algvere PV, Gouras P, Dafgard Kopp E. Long-term outcome of RPE allografts in non-immunosuppressed patients with AMD. Eur J Ophthalmol. 1999;9(3):217-30.

37. Morohoshi K, Goodwin AM, Ohbayashi M, Ono SJ. Autoimmunity in retinal degeneration: autoimmune retinopathy and age-related macular degeneration. J Autoimmun. 2009;33(3):247-54.

38. Rezai KA, Semnani RT, Patel SC, Ernest JT, van Seventer GA. The immunogenic potential of human fetal retinal pigment epithelium and its relation to transplantation. Invest Ophthalmol Vis Sci. 1997;38(12):2662-71

39. Kohen L, Enzmann V, Faude F, Wiedemann P. Mechanisms of graft rejection in the transplantation of retinal pigment epithelial cells. Ophthalmic Res. 1997;29(5):298-304.

40. Binder S, Stanzel BV, Krebs I, Glittenberg C. Transplantation of the RPE in AMD. Prog Retin Eye Res. 2007;26(5):516-54.

41. da Cruz L, Chen FK, Ahmado A, Greenwood J, Coffey P. RPE transplantation and its role in retinal disease. Prog Retin Eye Res. 2007;26(6):598-635.

42. Binder S, Stolba U, Krebs I, et al. Transplantation of autologous retinal pigment epithelium in eyes with foveal neovascularization resulting from age-related macular degeneration: a pilot study. Am J Ophthalmol. 2002;133(2):215-25.

43. Binder S, Krebs I, Hilgers RD, et al. Outcome of transplantation of autologous retinal pigment epithelium in age-related macular degeneration: a prospective trial. Invest Ophthalmol Vis Sci. 2004;45(11):4151-60.

44. Tezel TH, Del Priore LV, Kaplan HJ. Reengineering of aged Bruch's membrane to enhance retinal pigment epithelium repopulation. Invest Ophthalmol Vis Sci. 2004;45(9):3337-48.

45. Tezel TH, Kaplan HJ, Del Priore LV. Fate of human retinal pigment epithelial cells seeded onto layers of human Bruch's membrane. Invest Ophthalmol Vis Sci. 1999;40(2):467-76.

46. Diniz B, Thomas P, Thomas B, et al. Subretinal implantation of retinal pigment epithelial cells derived from human embryonic stem cells: improved survival when implanted as a monolayer. Invest Ophthalmol Vis Sci. 2013;54(7):5087-96. This is the first report that compared long-term survival of monolayer RPE sheet on a scaffold versus RPE cell suspension in a rodent model. Authors show that monolayer RPE sheet survives longer compared to the cell suspension which forms aggregates when transplanted in the sub-retinal space.

47. Lane C, Boulton M, Marshall J. Transplantation of retinal pigment epithelium using a pars plana approach. Eye (Lond). 1989;3(Pt 1): 27-32.

48. van Meurs JC, ter Averst E, Hofland LJ, et al. Autologous peripheral retinal pigment epithelium translocation in patients with subfoveal neovascular membranes. Br J Ophthalmol. 2004;88(1):110-3. 
49. Stanga PE, Kychenthal A, Fitzke FW, et al. Retinal pigment epithelium translocation and central visual function in age related macular degeneration: preliminary results. Int Ophthalmol. 2001;23(4-6):297-307.

50. MacLaren RE, Bird AC, Sathia PJ, Aylward GW. Long-term results of submacular surgery combined with macular translocation of the retinal pigment epithelium in neovascular age-related macular degeneration. Ophthalmology. 2005;112(12):2081-7.

51. Joussen AM, Heussen FMA, Joeres S, et al. Autologous translocation of the choroid and retinal pigment epithelium in age-related macular degeneration. Am J Ophthalmol. 2006;142(1):17-30. e8.

52. Ma Z, Han L, Wang C, et al. Autologous transplantation of retinal pigment epithelium-Bruch's membrane complex for hemorrhagic age-related macular degeneration. Invest Ophthalmol Vis Sci. 2009;50(6):2975-81.

53. Bindewald A, Roth F, Van Meurs J, Holz FG. Transplantation of retinal pigment pithelium (RPE) following CNV removal in patients with AMD. Techniques, results, outlook. Ophthalmologe. 2004;101(9):886-94.

54. MacLaren RE, Uppal GS, Balaggan KS, et al. Autologous transplantation of the retinal pigment epithelium and choroid in the treatment of neovascular age-related macular degeneration. Ophthalmology. 2007;114(3):561-70.

55. Treumer F, Bunse A, Klatt C, et al. Autologous retinal pigment epithelium-choroid sheet transplantation in age related macular degeneration: morphological and functional results. Br J Ophthalmol. 2007;91(3):349-53.

56. Joussen AM, Joeres S, Fawzy N, et al. Autologous translocation of the choroid and retinal pigment epithelium in patients with geographic atrophy. Ophthalmology. 2007;114(3):551-60.

57. van Zeeburg EJ, Maaijwee KJ, Missotten TO, Heimann H, van Meurs JC. A free retinal pigment epithelium-choroid graft in patients with exudative age-related macular degeneration: results up to 7 years. Am J Ophthalmol. 2012;153(1):120-7. e2.

58. Maaijwee K, Heimann H, Missotten T, Mulder P, Joussen A, van Meurs J. Retinal pigment epithelium and choroid translocation in patients with exudative age-related macular degeneration: longterm results. Graefes Arch Clin Exp Ophthalmol. 2007;245(11): 1681-9.

59. Thomson JA, Itskovitz-Eldor J, Shapiro SS, et al. Embryonic stem cell lines derived from human blastocysts. Science. 1998;282(5391):1145-7.

60. Takahashi K, Tanabe K, Ohnuki M, et al. Induction of pluripotent stem cells from adult human fibroblasts by defined factors. Cell. 2007;131(5):861-72.

61. Yu J, Vodyanik MA, Smuga-Otto K, et al. Induced pluripotent stem cell lines derived from human somatic cells. Science. 2007;318(5858):1917-20.

62. Hong S, Winkler T, Wu C, et al. Path to the clinic: assessment of iPSC-based cell therapies in vivo in a nonhuman primate model. Cell Rep. 2014;7(4):1298-309.

63. Kawasaki H, Suemori H, Mizuseki K, et al. Generation of dopaminergic neurons and pigmented epithelia from primate ES cells by stromal cell-derived inducing activity. Proc Natl Acad Sci USA. 2002;99(3):1580-5.

64. Haruta M, Sasai Y, Kawasaki H, et al. In vitro and in vivo characterization of pigment epithelial cells differentiated from primate embryonic stem cells. Invest Ophthalmol Vis Sci. 2004;45(3): 1020-5.

65. Klimanskaya I, Hipp J, Rezai KA, West M, Atala A, Lanza R. Derivation and comparative assessment of retinal pigment epithelium from human embryonic stem cells using transcriptomics. Cloning Stem Cells. 2004;6(3):217-45.

66. Osakada F, Ikeda H, Sasai Y, Takahashi M. Stepwise differentiation of pluripotent stem cells into retinal cells. Nat Protoc. 2009;4(6):811-24.
67. Idelson M, Alper R, Obolensky A, et al. Directed differentiation of human embryonic stem cells into functional retinal pigment epithelium cells. Cell Stem Cell. 2009;5(4):396-408.

68. Reh TA, Lamba D, Gust J. Directing human embryonic stem cells to a retinal fate. Cellular Programming and Reprogramming. 2010;636:139-53.

69. Lane A, Philip LR, Ruban L, et al. Engineering efficient retinal pigment epithelium differentiation from human pluripotent stem cells. Stem Cells Transl Med. 2014;3(11):1295-304.

70. Vaajasaari H, Ilmarinen T, Juuti-Uusitalo K, et al. Toward the defined and xeno-free differentiation of functional human pluripotent stem cell-derived retinal pigment epithelial cells. Mol Vis. 2011;17:558-75.

71. Buchholz DE, Pennington BO, Croze RH, Hinman CR, Coffey PJ, Clegg DO. Rapid and efficient directed differentiation of human pluripotent stem cells into retinal pigmented epithelium. Stem Cells Transl Med. 2013;2(5):384-93.

72. Lund RD, Wang S, Klimanskaya I, et al. Human embryonic stem cell-derived cells rescue visual function in dystrophic RCS rats. Cloning Stem Cells. 2006;8(3):189-99.

73. Schwartz SD, Hubschman J, Heilwell G, et al. Embryonic stem cell trials for macular degeneration: a preliminary report. Lancet. 2012;379(9817):713-20.

74. Lu B, Malcuit C, Wang S, et al. Long-term safety and function of RPE from human embryonic stem cells in preclinical models of macular degeneration. Stem Cells. 2009;27(9):2126-35.

75. Carr A, Vugler AA, Hikita ST, et al. Protective effects of human iPS-derived retinal pigment epithelium cell transplantation in the retinal dystrophic rat. PLoS One. 2009;4(12):e8152.

76. $\mathrm{Hu} \mathrm{Y}$, Liu L, Lu B, et al. A novel approach for subretinal implantation of ultrathin substrates containing stem cell-derived retinal pigment epithelium monolayer. Ophthalmic Res. 2012;48(4):186-91.

77. Schwartz SD, Regillo CD, Lam BL, et al. Human embryonic stem cell-derived retinal pigment epithelium in patients with age-related macular degeneration and Stargardt's macular dystrophy: followup of two open-label phase 1/2 studies. Lancet. 2015;385:509-16.

78. Ho TC, Del Priore LV. Reattachment of cultured human retinal pigment epithelium to extracellular matrix and human Bruch's membrane. Invest Ophthalmol Vis Sci. 1997;38(6):1110-8.

79. Pruett RC, Weiter JJ, Goldstein RB. Myopic cracks, angioid streaks, and traumatic tears in Bruch's membrane. Am J Ophthalmol. 1987;103(4):537-43.

80. Bhatt NS, Newsome DA, Fenech T, et al. Experimental transplantation of human retinal pigment epithelial cells on collagen substrates. Am J Ophthalmol. 1994;117(2):214-21.

81. Thumann G, Hueber A, Dinslage S, et al. Characteristics of iris and retinal pigment epithelial cells cultured on collagen type I membranes. Curr Eye Res. 2006;31(3):241-9.

82. Lu JT, Lee CJ, Bent SF, Fishman HA, Sabelman EE. Thin collagen film scaffolds for retinal epithelial cell culture. Biomaterials. 2007;28(8):1486-94.

83. Del Priore LV, Tezel TH, Kaplan HJ. Survival of allogeneic porcine retinal pigment epithelial sheets after subretinal transplantation. Invest Ophthalmol Vis Sci. 2004;45(3):985-92.

84. Ho T, Del Priore LV, Kaplan HJ. En bloc transfer of extracellular matrix in vitro. Curr Eye Res. 1996;15(9):991-7.

85. Oganesian A, Gabrielian K, Ernest JT, Patel SC. A new model of retinal pigment epithelium transplantation with microspheres. Arch Ophthalmol. 1999;117(9):1192-200.

86. Sugino IK, Sun Q, Wang J, et al. Comparison of FRPE and human embryonic stem cell-derived RPE behavior on aged human Bruch's membrane. Invest Ophthalmol Vis Sci. 2011;52(8):4979-97.

87. Thumann G, Schraermeyer U, Bartz-Schmidt KU, Heimann K. Descemet's membrane as membranous support in RPE/IPE transplantation. Curr Eye Res. 1997;16(12):1236-8. 
88. Hartmann U, Sistani F, Steinhorst U. Human and porcine anterior lens capsule as support for growing and grafting retinal pigment epithelium and iris pigment epithelium. Graefes Arch Clin Exp Ophthalmol. 1999;237(11):940-5.

89. Nicolini J, Kiilgaard JF, Wiencke AK, et al. The anterior lens capsule used as support material in RPE cell-transplantation. Acta Ophthalmol Scand. 2000;78(5):527-31.

90. Lee CJ, Huie P, Leng T, et al. Microcontact printing on human tissue for retinal cell transplantation. Arch Ophthalmol. 2002;120(12):1714-8.

91. Farrokh-Siar L, Rezai KA, Patel SC, Ernest TT. Cryoprecipitate: an autologous substrate for human fetal retinal pigment epithelium. Curr Eye Res. 1999;19(2):89-94.

92. Capeans C, Pineiro A, Pardo M, et al. Amniotic membrane as support for human retinal pigment epithelium (RPE) cell growth. Acta Ophthalmol Scand. 2003;81(3):271-7.

93. Singhal S, Vemuganti GK. Primary adult human retinal pigment epithelial cell cultures on human amniotic membranes. Indian J Ophthalmol. 2005;53(2):109-13.

94. Stanzel BV, Espana EM, Grueterich M, et al. Amniotic membrane maintains the phenotype of rabbit retinal pigment epithelial cells in culture. Exp Eye Res. 2005;80(1):103-12.

95. Ohno-Matsui K, Ichinose $\mathrm{S}$, Nakahama $\mathrm{K}$, et al. The effects of amniotic membrane on retinal pigment epithelial cell differentiation. Mol Vis. 2005;11(6):1-10.

96. Beutel J, Greulich L, Lüke M, et al. Inner limiting membrane as membranous support in RPE sheet-transplantation. Graefes Arch Clin Exp Ophthalmol. 2007;245(10):1469-73.

97. Shadforth A, George KA, Kwan AS, Chirila TV, Harkin DG. The cultivation of human retinal pigment epithelial cells on $<\mathrm{i}>$ Bombyx mori</i>silk fibroin. Biomaterials. 2012;33(16):4110-7.

98. Xiang P, Wu K, Zhu Y, et al. A novel Bruch's membrane-mimetic electrospun substrate scaffold for human retinal pigment epithelium cells. Biomaterials. 2014;35:9777-88.

99. Liu Z, Yu N, Holz FG, Yang F, Stanzel BV. Enhancement of retinal pigment epithelial culture characteristics and subretinal space tolerance of scaffolds with $200 \mathrm{~nm}$ fiber topography. Biomaterials. 2014;35(9):2837-50.

100. Treharne AJ, Thomson HAJ, Grossel MC, Lotery AJ. Developing methacrylate-based copolymers as an artificial Bruch's membrane substitute. J Biomed Mater Res A. 2012;100A(9):2358-64.

101. Srivastava GK, Martín L, Singh AK, et al. Elastin-like recombinamers as substrates for retinal pigment epithelial cell growth. J Biomed Mater Res A. 2011;97(3):243-50.

102. Singh AK, Srivastava GK, Martín L, Alonso M, Pastor JC. Bioactive substrates for human retinal pigment epithelial cell growth from elastin-like recombinamers. J Biomed Mater Res A. 2014;102(3):639-46.

103. Thomson RC, Giordano GG, Collier JH, et al. Manufacture and characterization of poly ( $\alpha$-hydroxy ester) thin films as temporary substrates for retinal pigment epithelium cells. Biomaterials. 1996;17(3):321-7.

104. Giordano GG, Thomson RC, Ishaug SL, et al. Retinal pigment epithelium cells cultured on synthetic biodegradable polymers. J Biomed Mater Res. 1997;34(1):87-93.

105. Hadlock T, Singh S, Vacanti J, McLaughlin BJ. Ocular cell monolayers cultured on biodegradable substrates. Tissue Eng. 1999;5(3):187-96.

106. Lu L, Garcia CA, Mikos AG. Retinal pigment epithelium cell culture on thin biodegradable poly (DL-lactic-co-glycolic acid) films. J Biomater Sci Polym Ed. 1998;9(11):1187-205.

107. Williams R, Krishna Y, Dixon S, Haridas A, Grierson I, Sheridan C. Polyurethanes as potential substrates for sub-retinal retinal pigment epithelial cell transplantation. J Mater Sci Mater Med. 2005;16(12):1087-92.
108. Carr AF, Smart MJK, Ramsden CM, Powner MB, da Cruz L, Coffey PJ. Development of human embryonic stem cell therapies for age-related macular degeneration. Trends Neurosci. 2013;36(7):385-95.

109. Stanzel BV, Liu Z, Brinken R, Braun N, Holz FG, Eter N. Subretinal delivery of ultrathin rigid-elastic cell carriers using a metallic shooter instrument and biodegradable hydrogel encapsulation. Invest Ophthalmol Vis Sci. 2012;53(1):490-500. In this report authors use a special transplantation device that allows an easier and reproducible transplantation of RPE tissue in the sub-retinal space in animal models. Such tool will facilitate pre-clinical work with novel RPE tissues developed by investigators.

110. Stanzel BV, Liu Z, Somboonthanakij S, et al. Human RPE stem cells grown into polarized RPE monolayers on a polyester matrix are maintained after grafting into rabbit subretinal space. Stem Cell Rep. 2014;2(1):64-77.

111. Sorkio A, Hongisto H, Kaarniranta K, Uusitalo H, Juuti-Uusitalo K, Skottman H. Structure and barrier properties of human embryonic stem cell-derived retinal pigment epithelial cells are affected by extracellular matrix protein coating. Tissue Eng Part A. 2014;20(3-4):622-34.

112. Tezcaner A, Bugra K, Hasırcı V. Retinal pigment epithelium cell culture on surface modified poly (hydroxybutyrate-cohydroxyvalerate) thin films. Biomaterials. 2003;24(25): 4573-83.

113. Krishna Y, Sheridan C, Kent D, Kearns V, Grierson I, Williams R. Expanded polytetrafluoroethylene as a substrate for retinal pigment epithelial cell growth and transplantation in age-related macular degeneration. $\mathrm{Br} \mathrm{J}$ Ophthalmol. 2011;95(4):569-73.

114. McHugh KJ, Tao SL, Saint-Geniez M. Porous poly(epsiloncaprolactone) scaffolds for retinal pigment epithelium transplantation. Invest Ophthalmol Vis Sci. 2014;55(3):1754-62.

115. Lu B, Tai YC, Humayun MS. Microdevice-based cell therapy for age-related macular degeneration. Dev Ophthalmol. 2014;53:15566.

116. Wu H, Li X, Dong J, Pei W, Chen H. Effects of subretinal implant materials on the viability, apoptosis and barrier function of cultured RPE cells. Graefes Arch Clin Exp Ophthalmol. 2007;245(1): 135-42.

117. Subrizi A, Hiidenmaa H, Ilmarinen T, et al. Generation of hESCderived retinal pigment epithelium on biopolymer coated polyimide membranes. Biomaterials. 2012;33(32):8047-54.

118. Binder S. Scaffolds for retinal pigment epithelium (RPE) replacement therapy. Br J Ophthalmol. 2011;95(4):441-2.

119. Hynes SR, Lavik EB. A tissue-engineered approach towards retinal repair: scaffolds for cell transplantation to the subretinal space. Graefes Arch Clin Exp Ophthalmol. 2010;248(6):763-78.

120. Treharne AJ, Grossel MC, Lotery AJ, Thomson HA. The chemistry of retinal transplantation: the influence of polymer scaffold properties on retinal cell adhesion and control. Br J Ophthalmol. 2011;95(6):768-73.

121. Sponsor Institutes: Pfizer and University College London. A study of implantation of human embryonic stem cell derived retinal pigment epithelium in subjects with acute wet age related macular degeneration and recent rapid vision decline. http://www. clinicaltrials.gov/ct2/show/NCT01691261?term=rpe\&rank=11. Accessed 11/16 2014.

122. Kamao H, Mandai M, Okamoto S, et al. Characterization of human induced pluripotent stem cell-derived retinal pigment epithelium cell sheets aiming for clinical application. Stem Cell Rep. 2014;2(2):205-18. This is the first report testing autologous and allogeneic iPSC-derived RPE sheets in monkey models. Authors were able to transplant RPE sheets without any additional scaffold. They demonstrate that autologous cells have 
better survival in monkey models. This work led to the first in human iPSC-derived RPE sheet transplant in 2014.

123. Reardon S, Cyranoski D. Japan stem-cell trial stirs envy. Nature. 2014;513(7518):287-8.

124. Kubota A, Nishida K, Yamato M, et al. Transplantable retinal pigment epithelial cell sheets for tissue engineering. Biomaterials. 2006;27(19):3639-44.

125. von Recum HA, Okano T, Kim SW, Bernstein PS. Maintenance of retinoid metabolism in human retinal pigment epithelium cell culture. Exp Eye Res. 1999;69(1):97-107.

126. von Recum H, Kikuchi A, Yamato M, Sakurai Y, Okano T, Kim SW. Growth factor and matrix molecules preserve cell function on thermally responsive culture surfaces. Tissue Eng. 1999;5(3):25165.

127. Yaji N, Yamato M, Yang J, Okano T, Hori S. Transplantation of tissue-engineered retinal pigment epithelial cell sheets in a rabbit model. Biomaterials. 2009;30(5):797-803.
128. Riolobos L, Hirata RK, Turtle CJ, et al. HLA engineering of human pluripotent stem cells. Mol Ther. 2013;21(6):1232-41.

129. Andrews PW, Cavanagro, J, Deans, R, et al. Harmonizing standards for producing clinical-grade therapies from pluripotent stem cells. Nat Biotechnol. 2014;32:724-6.

130. Turner M, Leslie S, Martin NG, et al. Toward the development of a global induced pluripotent stem cell library. Cell Stem Cell. 2013;13(4):382-4.

131. Eiraku M, Takata N, Ishibashi H, et al. Self-organizing optic-cup morphogenesis in three-dimensional culture. Nature. 2011;472(7341):51-6.

132. Zhong X, Gutierrez C, Xue T, et al. Generation of threedimensional retinal tissue with functional photoreceptors from human iPSCs. Nat Commun. 2014;5:4047.

133. Bharti K, Rao M, Hull SC, et al. Developing cellular therapies for retinal degenerative diseases. Invest Ophthalmol Vis Sci. 2014;55(2):1191-202. 